\title{
Stronger Effect of Azilsartan on Reduction of Proteinuria Compared to Candesartan in Patients with CKD: A Randomized Crossover Trial
}

\author{
Takaichi Suehiro a, b Kazuhiko Tsuruyaa, c, d Hisako Yoshidac, e \\ Hiroaki Tsujikawa ${ }^{a}$ Shunsuke Yamada ${ }^{a}$ Shigeru Tanaka ${ }^{a}$ Akihiro Tsuchimoto ${ }^{a}$ \\ Masahiro Eriguchi ${ }^{a}$ d Kiichiro Fujisaki ${ }^{a, f}$ Kumiko Torisu ${ }^{a, c}$ Toshiaki Nakano ${ }^{a}$ \\ Takanari Kitazono ${ }^{a}$ \\ aDepartment of Medicine and Clinical Science, Graduate School of Medical Sciences, Kyushu University, Fukuoka, \\ Japan; ' Department of Nephrology, Harasanshin Hospital, Fukuoka, Japan; 'Department of Integrated Therapy for \\ Chronic Kidney Disease, Graduate School of Medical Sciences, Kyushu University, Fukuoka, Japan; dDepartment \\ of Nephrology, Nara Medical University, Kashihara, Japan; 'Department of Medical Statistics, Osaka City University \\ Graduate School of Medicine, Osaka, Japan; fDepartment of Nephrology, lizuka Hospital, lizuka, Japan
}

\section{Keywords}

Azilsartan · Candesartan · CKD · Crossover trial · Proteinuria

\begin{abstract}
Introduction: Angiotensin receptor blockers (ARBs) are preferably used in hypertensive patients with CKD. Azilsartan is a strong antihypertensive ARB, but its antiproteinuric effects are not well understood. We compared the antiproteinuric effect of azilsartan and candesartan in CKD patients in an open-label, randomized, crossover trial. Methods: A total of 111 patients were treated with $20 \mathrm{mg}$ of azilsartan daily for 2 months as a run-in period. After the run-in period, patients were randomized into 2 arms and received either $20 \mathrm{mg}$ of azilsartan or $8 \mathrm{mg}$ of candesartan daily for 3 months in a crossover trial. The primary outcome was the percent change in urinary protein-to-Cr ratio (UPCR). Results: Ninety-five patients completed the trial. The mean age was 64.3 years. The estimated glomerular filtration rate (eGFR) and UPCR were
\end{abstract}

karger@karger.com www.karger.com/kbr

Karger $\stackrel{\text { ' }}{5}$

GOPEN ACCESS
(C) 2021 The Author(s)

Published by S. Karger AG, Basel

This article is licensed under the Creative Commons AttributionNonCommercial-NoDerivatives 4.0 International License (CC BYNC-ND) (http://www.karger.com/Services/OpenAccessLicense) Usage and distribution for commercial purposes as well as any distribution of modified material requires written permission.
$41.5 \mathrm{~mL} / \mathrm{min} / 1.73 \mathrm{~m}^{2}$ and $1.8 \mathrm{~g} / \mathrm{gCr}$, respectively. The baseline systolic and diastolic blood pressures were 131.4 and $71.0 \mathrm{~mm} \mathrm{Hg}$, respectively. The mean percent change in the UPCR was $-3.8 \%$ in the azilsartan group and $30.8 \%$ in the candesartan group at the 1 st endpoint $(p=0.0004)$, and $6.1 \%$ in the azilsartan group and $25.8 \%$ in the candesartan group at the $2 \mathrm{nd}$ (final) endpoint $(p=0.029)$. The incidence of adverse events, including eGFR levels and serum potassium levels, was not significantly different between the groups. Conclusion: A $20 \mathrm{mg}$ azilsartan dose had potent antiproteinuric effects compared with an $8 \mathrm{mg}$ candesartan dose, without an increase in adverse events. Azilsartan may provide renal protection in addition to antihypertensive effects in CKD patients.

(C) 2021 The Author(s).

Published by S. Karger AG, Basel

Takaichi Suehiro and Kazuhiko Tsuruya contributed equally to this work.
Kazuhiko Tsuruya

Department of Nephrology, Nara Medical University 840 Shijo-cho

Kashihara, Nara 634-8521 (Japan)

tsuruya@ naramed-u.ac.jp 


\section{Introduction}

Circulating and tissue angiotensin II are associated with the progression of $\mathrm{CKD}$, and angiotensin receptor blockers (ARBs) inhibit the effect of both circulating and tissue angiotensin II [1-3]. In clinical studies, ARBs decreased urinary protein excretion and blood pressure $[4$, 5], and a reduction in proteinuria was associated with better renal prognosis during ARB treatment. Therefore, ARBs are used as one of the first-line therapies in hypertensive patients with CKD. It was reported that increasing ARB levels above the usual doses produced increased antiproteinuric effects in patients with CKD $[6,7]$. However, the doses of ARB used in clinical situations are limited. Furthermore, the addition of angiotensin-converting enzyme (ACE) inhibitors or renin inhibitors to ARBs for further inhibition of the effect of angiotensin II increased adverse events $[8,9]$. Therefore, further inhibition of the effect of angiotensin II is difficult to achieve in clinical situations. Azilsartan is reported to have superior antihypertensive effects compared with other ARBs, and this effect might be caused by its strong binding to the angiotensin II receptor compared with other ARBs [10]. We hypothesized that azilsartan has more potent antiproteinuric effects than older ARBs, such as candesartan. We compared azilsartan and candesartan, in a crossover manner, to assess whether azilsartan had stronger antiproteinuric effects in patients with CKD.

\section{Materials and Methods}

\section{Study Design}

This open-label, randomized, crossover trial comparing the efficacy of azilsartan and candesartan in regard to antiproteinuric and antihypertensive effects was conducted in 12 nephrology centers in Fukuoka, Japan. The renal effect of azilsartan and candesartan was compared. The study design is presented in Figure 1. At the beginning of the study, patients who met the inclusion criteria entered the 2-month run-in period. Patients discontinued any previously used ACE inhibitors or ARBs, and patients were treated using $20 \mathrm{mg}$ of azilsartan once a day. After the run-in period, patients who demonstrated potassium $\geq 5.5 \mathrm{mEq} / \mathrm{L}$, blood pressure $\geq 160 / 100 \mathrm{~mm} \mathrm{Hg}$, elevated Cr levels $\geq 30 \%$, or were judged to be unfit to continue the study by the primary doctor were excluded. The rest of the patients entered the 3 -month crossover period. $\mathrm{Pa}$ tients were randomized equally by an independent institution (Mebix Inc., Tokyo, Japan) (via a Web system) into 2 arms and received either $20 \mathrm{mg}$ of azilsartan or $8 \mathrm{mg}$ of candesartan in a crossover manner. Blood pressure, urinary protein-to- $\mathrm{Cr}$ ratio (UPCR), age, and the hospital of the study patient were used as stratification factors for randomization.

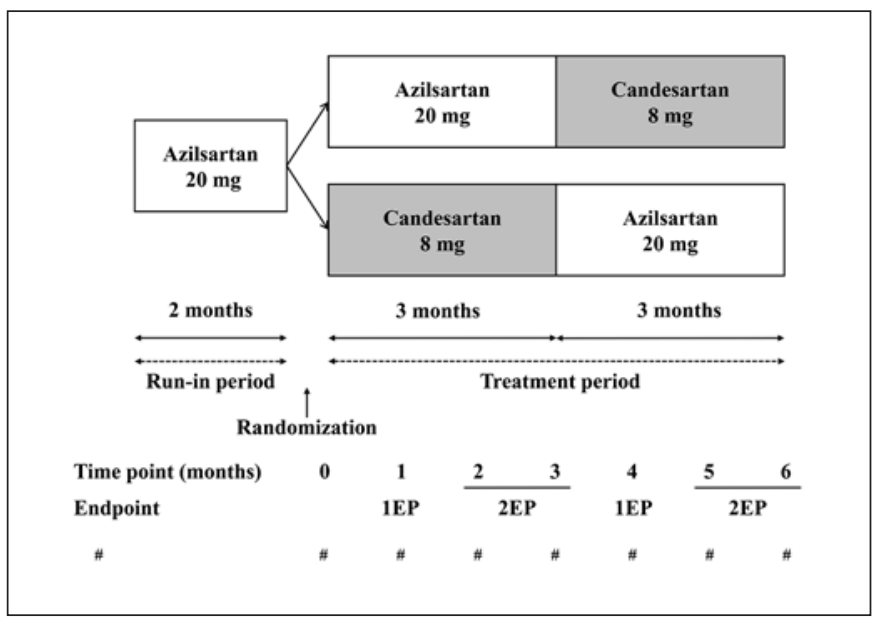

Fig. 1. Study design. \#, collected urine and blood samples, and measured blood pressure and pulse rate.

Addition of ACE inhibitors, ARBs, and renin inhibitors was not permitted. A change of antihypertensive medications, except for changes to ACE inhibitors, ARBs, and renin inhibitors, was permitted if the primary doctor assessed that it was required. Target blood pressure was under $130 / 80 \mathrm{~mm} \mathrm{Hg}$, in accordance with the guidelines of the Japanese Society of Nephrology [11].

This study was performed in accordance with the Declaration of Helsinki and was approved by the Independent Review Board of Kyusyu University Hospital (Approval number 24-023) and registered at the University Hospital Medical Information Network Clinical Trials Registry (UMIN-CTR; the trial identification number: UMIN000008597) in Japan. This study was also approved by an Ethics Committee in each study center. Patients were required to provide written informed consent. The discontinuation criteria included marked high and low blood pressure, cases where the primary doctor assessed that it was impossible to continue the study because of worsening of coexisting disorders or adverse events, hospitalization over 1 month, drug noncompliance, marked infrequent visits, withdrawal of consent, and any case where the primary doctor assessed that it was inappropriate to continue the study.

\section{Patients}

The inclusion criteria included patients who required antihypertensive drugs (defined as clinic systolic blood pressure $\geq 130$ $\mathrm{mm} \mathrm{Hg}$ and/or diastolic blood pressure $\geq 80 \mathrm{~mm} \mathrm{Hg}$ or receiving antihypertensive drugs), UPCR $\geq 0.3 \mathrm{~g} / \mathrm{gCr}$, estimated glomerular filtration rate $(e G F R) \geq 15 \mathrm{~mL} / \mathrm{min} / 1.73 \mathrm{~m}^{2}$, age more than 20 years, and outpatient status. The exclusion criteria included patients with known hypersensitivity to azilsartan or candesartan, myocardial infarction or stroke in the previous 6 months, serum potassium $\geq 5.5 \mathrm{mEq} / \mathrm{L}$, significant hepatic dysfunction (alanine aminotransferase was over 3 times the healthy upper limit), IgA nephropathy who were treated with steroid therapy during the previous year, known renal artery stenosis, severe nephrotic syndrome (serum albumin $<2.0 \mathrm{~g} / \mathrm{dL}$ ), severe infection, malignancy, pregnancy, and lactation. 


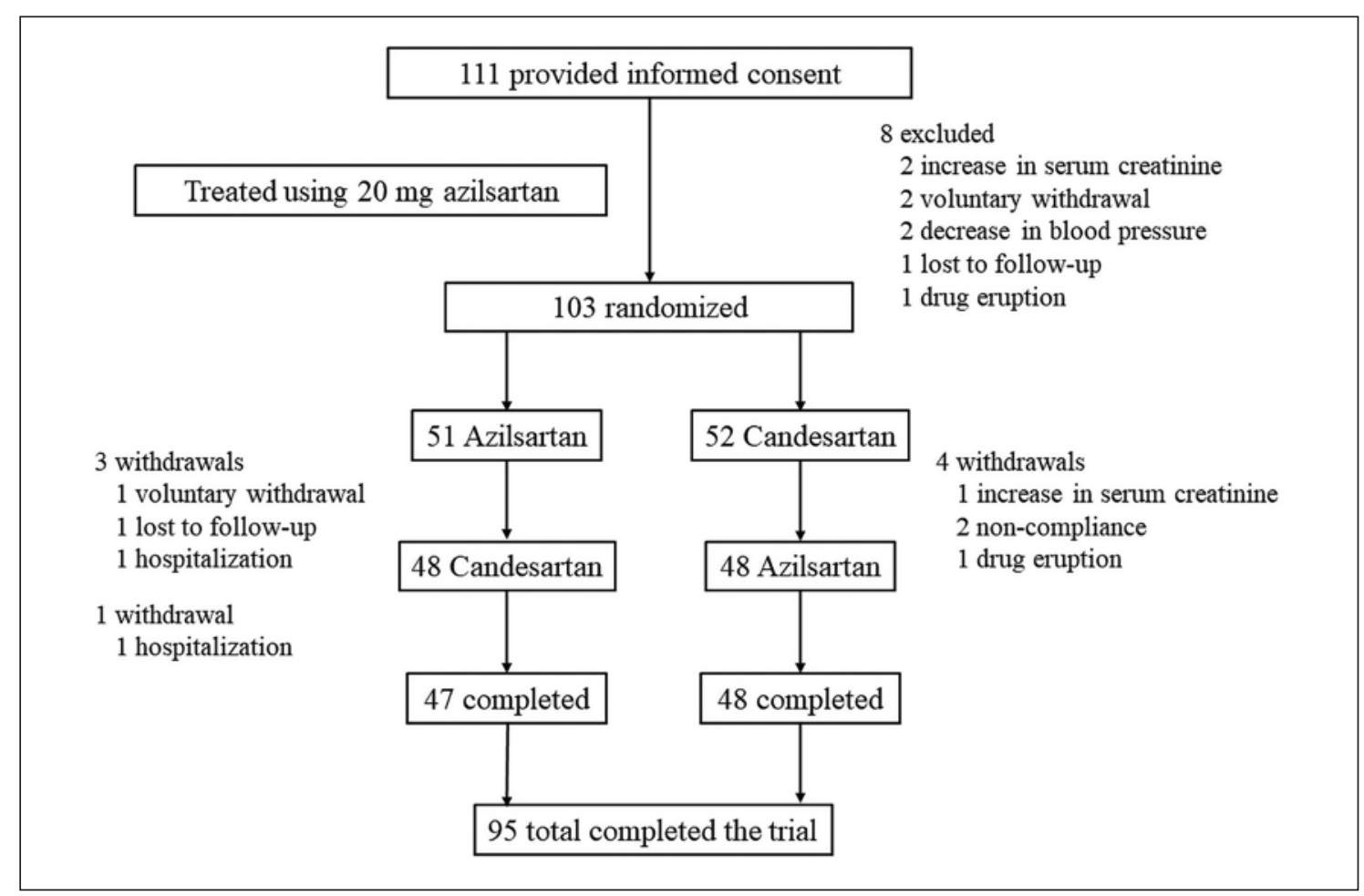

Fig. 2. Study flow diagram.

\section{Study Procedures}

During the crossover period, patient urine samples and blood samples were collected, and blood pressure and pulse rates were measured at $0,1,3,4$, and 6 months. For patients who needed to visit the hospital once a month for therapy, samples and data were also collected at 2 and 5 months. Systolic and diastolic blood pressures were evaluated in a sitting position after rest. The pulse rate was simultaneously assessed. Urine samples were collected to measure the UPCR, and blood samples were collected to measure hematological and biochemical parameters. All assays were performed using commercially available laboratory equipment. Renal function was assessed using a modified eGFR for Japanese patients [12].

\section{Study Outcomes}

We treated the data of 1 and 4 months as the first endpoint (1EP). To prevent variation in proteinuria, we averaged the UPCR and blood pressure data at 2 and 3 months and 5 and 6 months, and we treated the data as the UPCR and blood pressure at the second (final) endpoint (2EP). The primary outcome was the percent change in the UPCR at 1EP and 2EP. The secondary outcomes were the UPCR, systolic and diastolic blood pressures, the percent changes in systolic and diastolic blood pressures, and eGFR at 1EP and 2EP.

\section{Statistical Analysis}

Data from previous studies were used for sample size calculations. We expected that our patients would present with a mean proteinuria of approximately $1.7 \mathrm{~g} /$ day during ARB treatment [13]. On the basis of previous studies assessing additional reninangiotensin system (RAS) inhibition, we assumed a 15\% reduction in proteinuria mediated by azilsartan compared with candesartan $[6,14-17]$. We expected that the standard deviation of the percent change in the UPCR was 45 , based on our previous studies and studies of ARBs. We selected $80 \%$ as the power, and we used a significance level of $\alpha=0.05$. From these data, we estimated that 160 patients, including a $10 \%$ predicted dropout, were required to complete the crossover study to detect a statistically significant difference. To prevent errors resulting from the crossover design, the treatment periods were decided in random order. Because of this randomization and the short half-life of the intervention drugs (azilsartan: $11 \mathrm{~h}$, candesartan: $9 \mathrm{~h}$ ), the study protocol did not include washout periods $[18,19]$.

Data are expressed as mean \pm SD or number (percentage), if not otherwise mentioned. Treatment effect, carryover effect, and period effect were assessed using a repeated measures ANOVA. Linear regression analysis was performed to examine the correlation of 2 parameters. A difference was considered significant at $p<0.05$. Data were evaluated using JMP version 13.0 (SAS Institute, Cary, NC, USA).

\section{Results}

\section{Study Population}

A patient flow diagram is shown in Figure 2. We obtained informed consent from 111 patients who started the run-in period. During the run-in period, 8 patients discontinued. Of the 103 patients who were randomized, 
Table 1. Baseline characteristics of study subjects $(n=95)$

\begin{tabular}{|c|c|}
\hline Age, years & $64.3 \pm 12.9$ \\
\hline Male, $n(\%)$ & $64(67.3)$ \\
\hline Systolic blood pressure, $\mathrm{mm} \mathrm{Hg}$ & $131.4 \pm 18.3$ \\
\hline Diastolic blood pressure, $\mathrm{mm} \mathrm{Hg}$ & $71.0 \pm 12.5$ \\
\hline Pulse, per minute & $72.3 \pm 11.2$ \\
\hline $\mathrm{BMI}, \mathrm{kg} / \mathrm{m}^{2}$ & $24.6 \pm 5.8$ \\
\hline Diabetes mellitus, $n(\%)$ & $35(36.8)$ \\
\hline Cardiovascular disease, $n(\%)$ & $12(12.6)$ \\
\hline \multicolumn{2}{|l|}{ Renal diagnosis, $n(\%)$} \\
\hline Chronic glomerulonephritis & $50(52.6)$ \\
\hline Diabetic kidney disease & $13(13.7)$ \\
\hline Hypertensive nephropathy & $27(28.4)$ \\
\hline Others & $5(5.3)$ \\
\hline \multicolumn{2}{|c|}{ Medications, $n(\%)$} \\
\hline \multicolumn{2}{|c|}{ Other antihypertensive medication } \\
\hline Calcium antagonist & $68(71.6)$ \\
\hline Diuretic & $25(26.3)$ \\
\hline$\beta$ blocker & $14(14.7)$ \\
\hline$\alpha \beta$ blocker & $7(7.3)$ \\
\hline a blocker & $6(6.3)$ \\
\hline Aldosterone antagonist & $2(2.1)$ \\
\hline Lipid-lowering agent, $n(\%)$ & $47(49.5)$ \\
\hline Hemoglobin, g/dL & $12.6 \pm 1.9$ \\
\hline Serum Cr, mg/dL & $1.6 \pm 0.7$ \\
\hline $\mathrm{eGFR}, \mathrm{mL} / \mathrm{min} / 1.73 \mathrm{~m}^{2}$ & $41.5 \pm 19.7$ \\
\hline Serum sodium, $\mathrm{mmol} / \mathrm{L}$ & $140.8 \pm 2.4$ \\
\hline Serum potassium, $\mathrm{mmol} / \mathrm{L}$ & $4.6 \pm 0.5$ \\
\hline UPCR, g/gCr & $1.8 \pm 1.8$ \\
\hline Uric acid, mg/dL & $7.0 \pm 1.5$ \\
\hline Cr kinase, IU/L & $163.5 \pm 226.8$ \\
\hline Alanine aminotransferase, IU/L & $19.9 \pm 10.6$ \\
\hline
\end{tabular}

GFR, estimated glomerular filtration rate; UPCR, urinary protein-to-Cr ratio. Data are presented as mean $\pm \mathrm{SD}$ or value (percentage).

8 patients discontinued the study. Finally, 95 patients completed the study and were included in the analysis. The baseline characteristics of the study subjects are summarized in Table 1.

\section{Percent Change in Proteinuria (Primary Outcome)}

For the primary outcome, the mean percent change in the UPCR from baseline was $-3.8 \pm 7.9 \%$ in the azilsartan group and $30.8 \pm 7.9 \%$ in the candesartan group at $1 \mathrm{EP}$ $(p=0.0004)$, and $6.1 \pm 8.5 \%$ in the azilsartan group and $25.8 \pm 8.5 \%$ in the candesartan group at $2 \mathrm{EP}(p=0.029)$ (Fig. 3). No significant period effect or carryover effect was detected.

\section{Secondary Outcomes}

Systolic blood pressure at 1EP was lower in the azilsartan group (129.6 $\pm 1.9 \mathrm{~mm} \mathrm{Hg})$ than in the candesartan group $(134.8 \pm 1.9 \mathrm{~mm} \mathrm{Hg})(p=0.0007)$. The mean percent change in systolic blood pressure at $1 \mathrm{EP}$ was lower in the azilsartan group $(-0.6 \pm 1.3 \%)$ than in the candesartan group $(3.5 \pm 1.3 \%)(p=0.0006)$. Diastolic blood pressure at $1 \mathrm{EP}$ was lower in the azilsartan group (71.3 \pm $1.3 \mathrm{~mm} \mathrm{Hg})$ than in the candesartan group $(73.5 \pm 1.3 \mathrm{~mm}$ $\mathrm{Hg})(p=0.02)$. The mean percent change in diastolic blood pressure at 1EP was lower in the azilsartan group $(1.5 \pm 1.5 \%)$ than in the candesartan group $(5.1 \pm 1.5 \%)$ $(p=0.01)$. The mean UPCR at 1EP was lower in the azilsartan group $(1.6 \pm 0.2 \mathrm{~g} / \mathrm{gCr})$ than in the candesartan group (1.9 $\pm 0.2 \mathrm{~g} / \mathrm{gCr})(p=0.01)$ (Fig. 4$)$.

Systolic blood pressure at 2EP was lower in the azilsar$\tan$ group $(128.8 \pm 1.9 \mathrm{~mm} \mathrm{Hg})$ than in the candesartan group $(132.4 \pm 1.9 \mathrm{~mm} \mathrm{Hg})(p=0.01)$. The mean percent change in systolic blood pressure at 2EP was lower in the azilsartan group $(-1.4 \pm 1.2 \%)$ than in the candesartan group $(1.2 \pm 1.2 \%)(p=0.02)$. Diastolic blood pressure at 2EP was not significantly different between the azilsartan group $(71.4 \pm 1.3 \mathrm{~mm} \mathrm{Hg})$ and the candesartan group $(72.9 \pm 1.3 \mathrm{~mm} \mathrm{Hg})(p=0.1)$. The mean percent change in diastolic blood pressure at 2EP was not significantly different between the azilsartan group $(1.6 \pm 1.7 \%)$ and the candesartan group $(3.6 \pm 1.7 \%)(p=0.2)$. The mean UPCR at 2EP was not significantly different between the azilsartan group $(1.7 \pm 0.2 \mathrm{~g} / \mathrm{gCr})$ and the candesartan group (1.9 $\pm 0.2 \mathrm{~g} / \mathrm{gCr})(p=0.096)$ (Fig. 5).

The sequential changes in systolic blood pressure, diastolic blood pressure, and UPCR are shown in Figure 6. The participants of the solid line were treated with azilsartan for 3 months and then switched to candesartan. The participants of the dotted line were treated with candesartan for 3 months and then switched to azilsartan. The systolic blood pressures of the azilsartan- and candesartan-treated participants were $131.3 \pm 2.5$ and $130.5 \pm$ $2.3 \mathrm{~mm} \mathrm{Hg}$ at 3 months, and $126.4 \pm 2.6$ and $134.4 \pm 3.3$ $\mathrm{mm} \mathrm{Hg}$ at 6 months, respectively. The diastolic blood pressures of the azilsartan- and candesartan-treated participants were $70.9 \pm 1.9$ and $73.1 \pm 1.8 \mathrm{~mm} \mathrm{Hg}$ at 3 months, and $71.9 \pm 1.9$ and $72.7 \pm 2.0 \mathrm{~mm} \mathrm{Hg}$ at 6 months, respectively. The UPCR levels of the azilsartan- and candesartan-treated participants were $1.9 \pm 0.3$ and $1.7 \pm 0.3$ $\mathrm{g} / \mathrm{gCr}$ at 3 months, and $1.5 \pm 0.3$ and $2.1 \pm 0.3 \mathrm{~g} / \mathrm{gCr}$ at 6 months, respectively. The sequential changes in the percent changes in systolic blood pressure, diastolic blood pressure, and UPCR are shown in Figure 7. The mean percent changes in the systolic blood pressure of the azil- 


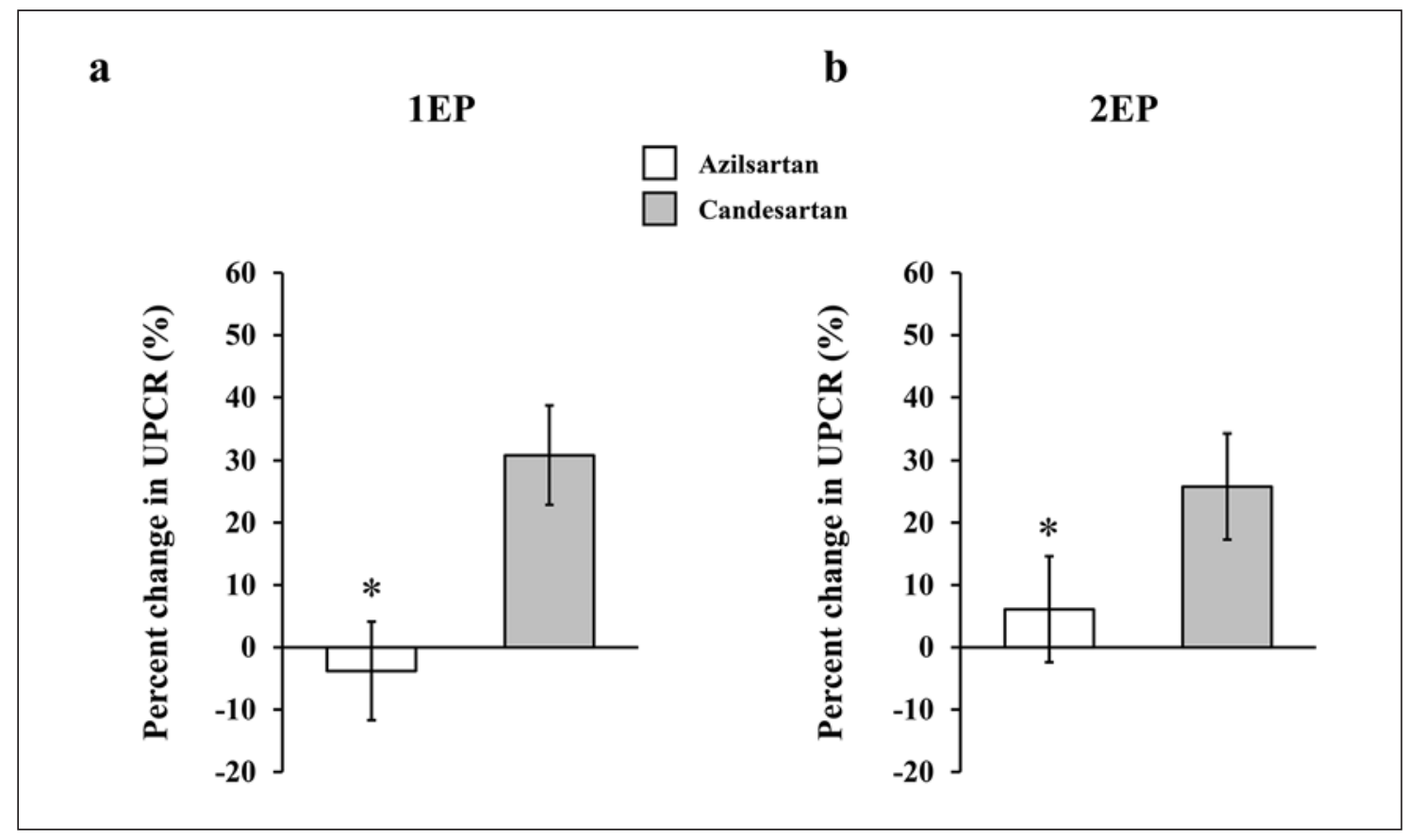

Fig. 3. Percent change in the UPCR in the azilsartan and candesartan groups from baseline at 1EP (a) and 2EP (b). ${ }^{*} p<0.05$ versus candesartan group. Data are expressed as mean \pm SEM. 1EP, the first endpoint; 2EP, the second endpoint; UPCR, urinary protein-to-Cr ratio.

a

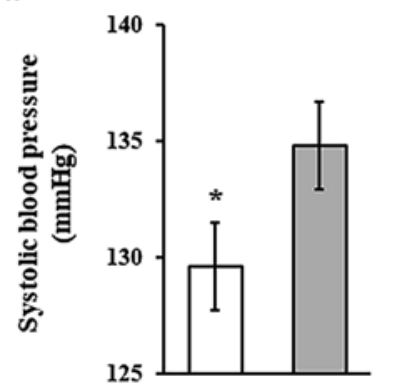

d

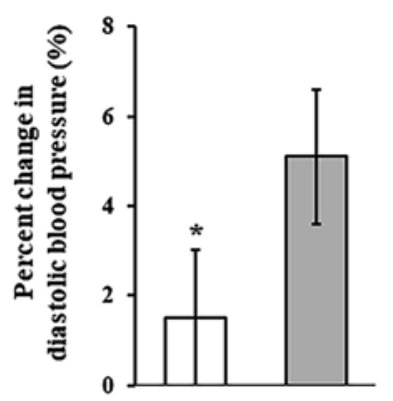

b

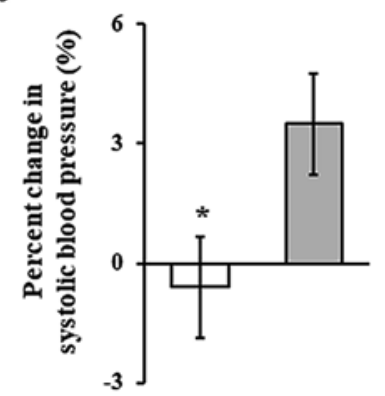

e

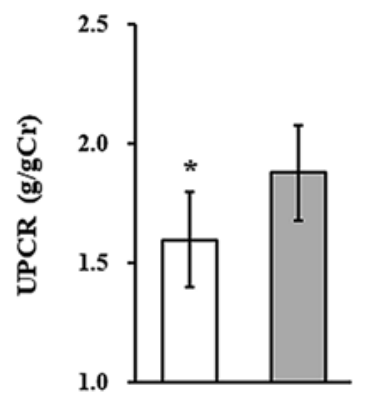

c

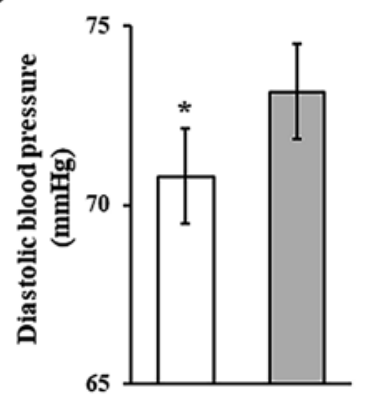

$\square$ Azilsartan

Candesartan

Fig. 4. Values at 1EP of the systolic blood pressure (a), percent change in systolic blood pressure (b), diastolic blood pressure (c), percent change in diastolic blood pressure (d), and UPCR (e) in the azilsartan and candesartan groups. ${ }^{*} p<0.05$ versus candesartan group. Data are expressed as mean \pm SEM. $1 \mathrm{EP}$, the first endpoint; UPCR, urinary protein-to-Cr ratio. 


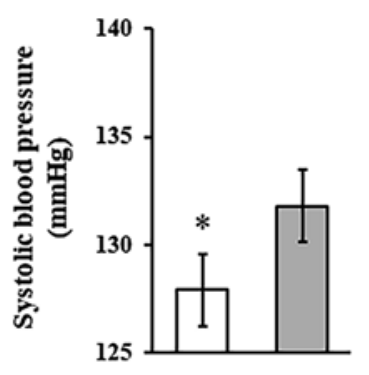

d

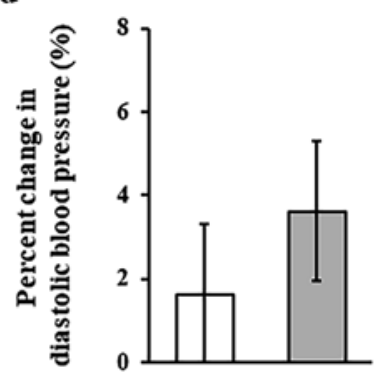

b
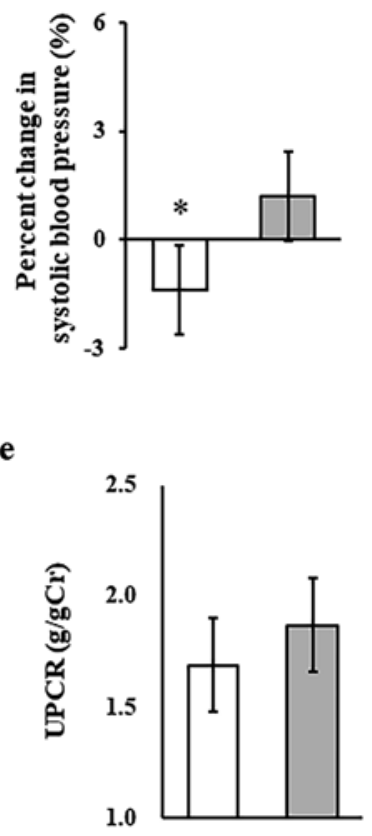

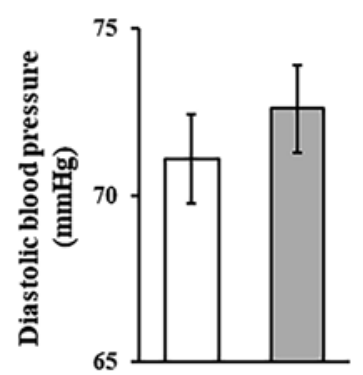

65

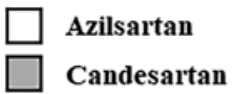

Fig. 5. Values at 2EP of the systolic blood pressure (a), percent change in systolic blood pressure (b), diastolic blood pressure (c), percent change in diastolic blood pressure (d), and UPCR (e) in the azilsartan and candesartan groups. ${ }^{*} p<0.05$ versus candesartan group. Data are expressed as mean \pm SEM. $2 \mathrm{EP}$, the second endpoint; UPCR, urinary protein-to-Cr ratio.

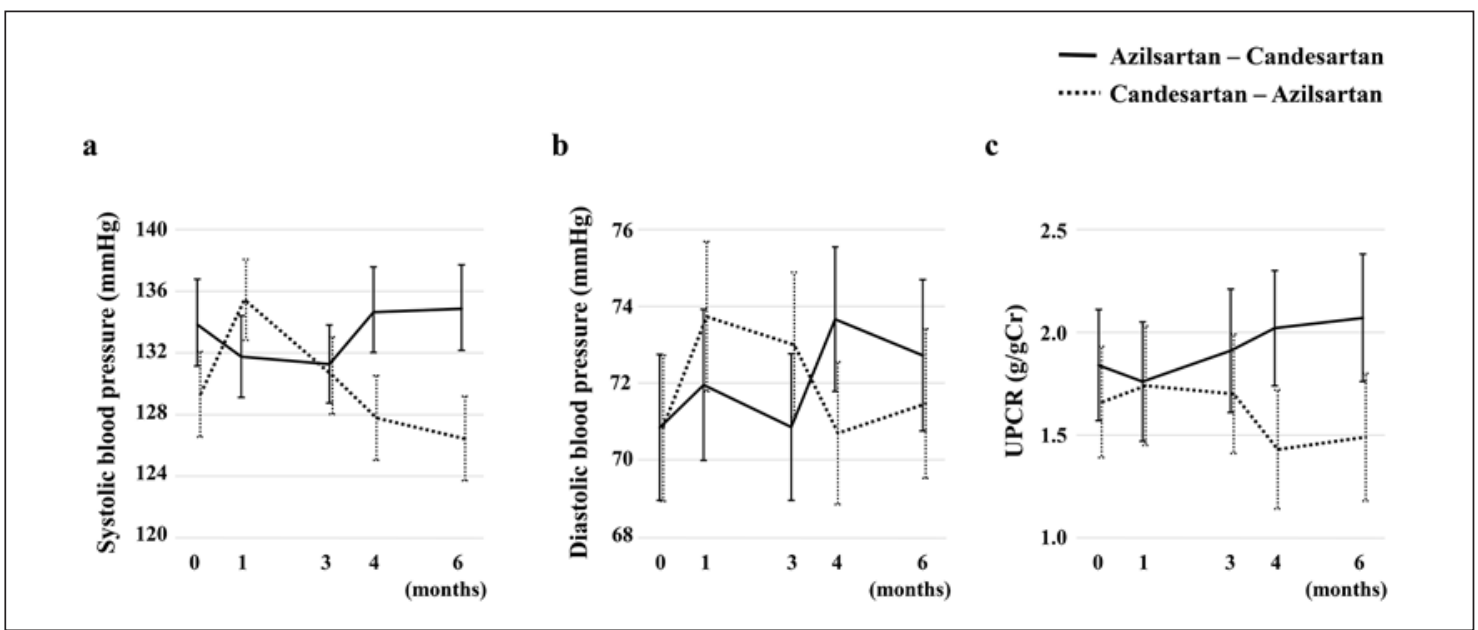

Fig. 6. Sequential changes in systolic blood pressure (a), diastolic blood pressure (b), and UPCR (c) of the azilsartan- and candesartan-treated participants. Data are expressed as mean \pm SEM. UPCR, urinary protein-to-Cr ratio. 


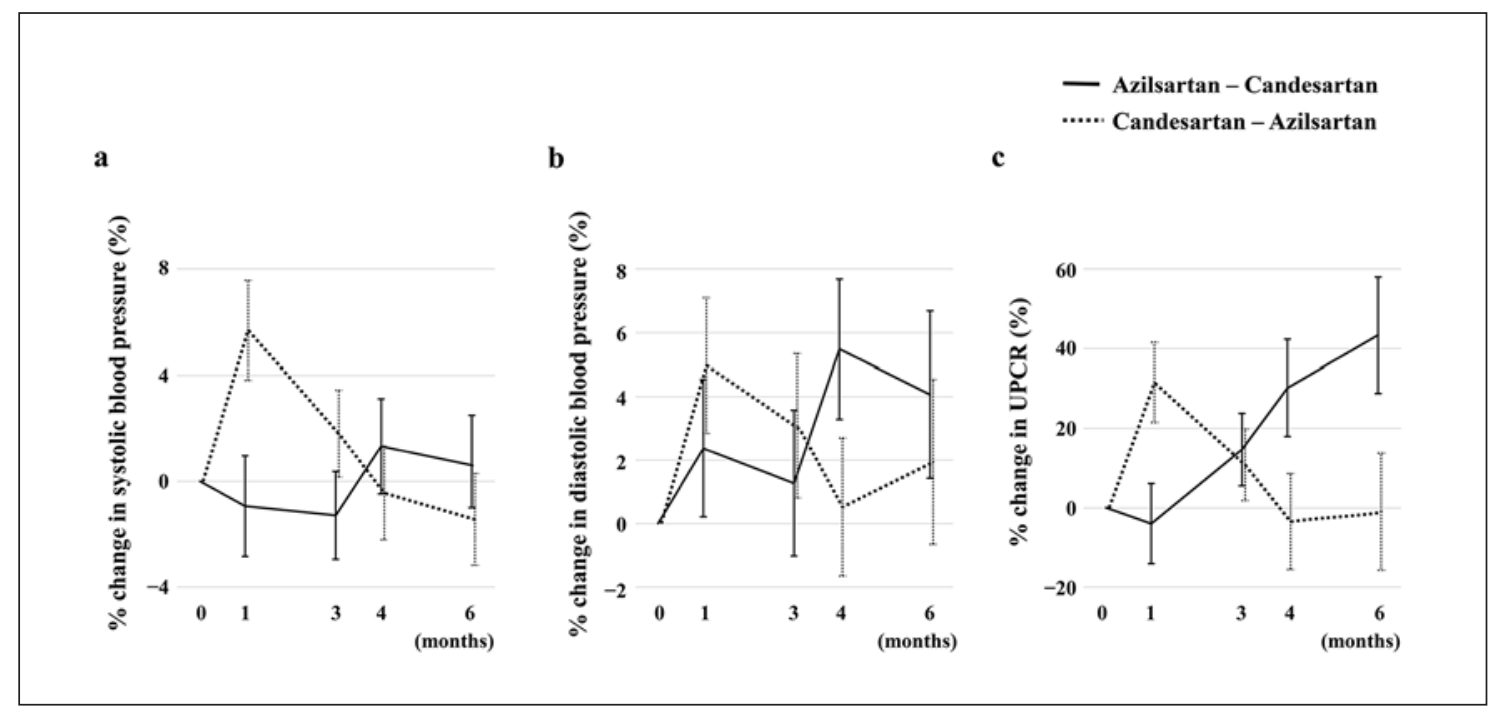

Fig. 7. Sequential changes in the percent changes in systolic blood pressure (a), diastolic blood pressure (b), and UPCR (c) of the azilsartan- and candesartan-treated participants. Data are expressed as mean \pm SEM. UPCR, urinary protein-to-Cr ratio.

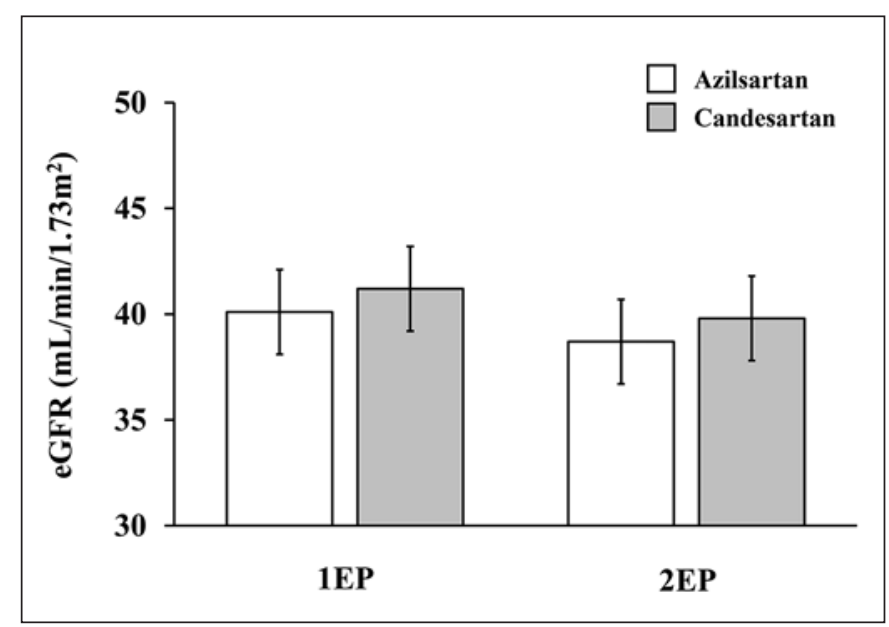

Fig. 8. eGFR in the azilsartan and candesartan groups at $1 \mathrm{EP}$ and 2EP. Data are expressed as mean \pm SEM. 1EP, the first endpoint; $2 \mathrm{EP}$, the second endpoint; eGFR, estimated glomerular filtration rate.

sartan- and candesartan-treated participants were $-1.3 \pm$ 1.7 and $1.8 \pm 1.5 \%$ at 3 months and $-1.5 \pm 1.7$ and $0.6 \pm$ $2.0 \%$ at 6 months, respectively. The mean percent changes of the diastolic blood pressure of the azilsartan- and candesartan-treated participants were $1.3 \pm 2.4$ and $3.2 \pm$ $2.1 \%$ at 3 months and $2.0 \pm 2.5$ and $4.1 \pm 2.6 \%$ at 6 months, respectively. The mean percent changes in the UPCR of

Antiproteinuric Effect of Azilsartan in CKD the azilsartan- and candesartan-treated participants were $14.7 \pm 9.7$ and $8.1 \pm 8.3 \%$ at 3 months and $-2.5 \pm 12.3$ and $43.4 \pm 16.5 \%$ at 6 months, respectively.

The mean eGFR levels at 1EP and 2EP were not significantly different between the azilsartan group (40.1 \pm $2.1,38.7 \pm 2.0 \mathrm{~mL} / \mathrm{min} / 1.73 \mathrm{~m}^{2}$, respectively) and the candesartan group $\left(41.3 \pm 2.1,39.8 \pm 2.0 \mathrm{~mL} / \mathrm{min} / 1.73 \mathrm{~m}^{2}\right.$, respectively) ( $p=0.12, p=0.10$ ) (Fig. 8). The percent change in UPCR was associated with the percent changes in systolic blood pressure $(r=0.33, p<0.0001)$ and diastolic pressure $(r=0.4, p<0.0001)$ at $1 \mathrm{EP}$. The percent change in UPCR was also associated with the percent changes in systolic blood pressure $(r=0.2, p=0.01)$ and diastolic pressure $(r=0.34, p<0.0001)$ at $2 \mathrm{EP}$.

\section{Side Effects and Change in Antihypertensive Drugs}

During the run-in period, 2 patients demonstrated increased Cr levels, 2 patients demonstrated decreased blood pressure, and 1 patient demonstrated drug eruption produced by azilsartan treatment. During the crossover period, 1 patient demonstrated increased Cr levels and 1 patient demonstrated drug eruption produced by candesartan treatment. One patient required hospitalization during both azilsartan and candesartan treatments. The study treatments were well tolerated by the majority of the study patients, and there was no apparent difference in the frequency of side effects between the azilsartan and candesartan groups during the crossover period. He- 
Table 2. Adverse effects during the study period

\begin{tabular}{lccl}
\hline & $\begin{array}{l}20 \mathrm{mg} \\
\text { azilsartan }\end{array}$ & $\begin{array}{l}8 \mathrm{mg} \\
\text { candesartan }\end{array}$ & $\begin{array}{l}p \\
\text { value }\end{array}$ \\
\hline Hemoglobin, g/dL & $12.6 \pm 0.2$ & $12.6 \pm 0.2$ & 0.6 \\
Serum Cr, mg/dL & $1.65 \pm 0.1$ & $1.62 \pm 0.1$ & 0.3 \\
Serum sodium, mmol/L & $140.7 \pm 0.3$ & $140.7 \pm 0.3$ & 0.9 \\
Serum potassium, mmol/L & $4.6 \pm 0.1$ & $4.5 \pm 0.1$ & 0.1 \\
Uric acid, mg/dL & $6.7 \pm 0.1$ & $6.7 \pm 0.1$ & 0.5 \\
Cr kinase, IU/L & $176.8 \pm 18.1$ & $146.7 \pm 18.1$ & 0.2 \\
Alanine aminotransferase, IU/L & $19.3 \pm 1.1$ & $19.9 \pm 1.1$ & 0.6 \\
\hline
\end{tabular}

Data are presented as mean \pm SEM.

matological and biochemical parameters related to adverse effects of ARBs were not significantly different between the azilsartan and candesartan groups during the study period (Table 2).

Antihypertensive drugs and diuretic drugs were changed during the crossover period. Antihypertensive drugs were decreased in 3 patients and increased in 1 patient during azilsartan treatment, and these drugs were increased in 3 patients during candesartan treatment. Diuretic drugs were decreased in 3 patients and increased in 1 patient during azilsartan treatment, and increased in 7 patients and decreased in 1 patient during candesartan treatment.

\section{Discussion}

The current study demonstrated that azilsartan $(20 \mathrm{mg}$ daily) treatment significantly decreased proteinuria and blood pressure compared with candesartan (8 mg daily) in patients with CKD who required hypertensive drugs. These significant reductions in proteinuria and blood pressure during azilsartan treatment were not associated with significant increases in side effects compared with candesartan. To the best of our knowledge, this is the first study of azilsartan in which the primary outcome is proteinuria. Furthermore, the level of proteinuria in the current study was higher than that in another study using azilsartan [18, 20-24]. We demonstrated that azilsartan had beneficial antiproteinuric and antihypertensive effects in patients with proteinuric CKD compared with candesartan, an older ARB.

$A R B s$ reduce proteinuria in patients with $C K D$ and have a reno-protective effect [16]. Therefore, ARBs are recommended for hypertensive patients with CKD by clinical guidelines. The reno-protective effect of azilsartan has not been well assessed. Shiga et al. [20] and Taka$\mathrm{mi}$ et al. [21] demonstrated that azilsartan $(20 \mathrm{mg})$ and olmesartan medoxomil ( $20 \mathrm{mg}$ ) decreased blood pressure equally, and both drugs decreased the urinary albuminto-Cr ratio equally. Kakio et al. [22] demonstrated that azilsartan $(20 \mathrm{mg})$ and olmesartan medoxomil $(20 \mathrm{mg})$ decreased blood pressure equally but only azilsartan significantly decreased urinary albumin. They suspected that the effect on glomerular efferent arterioles in the azilsartan group might be stronger than that in the olmesartan group. Takahara et al. [18] compared the blood pressure-lowering effects of azilsartan $(10 \mathrm{mg})$ and candesar$\tan (8 \mathrm{mg})$. They demonstrated that the blood pressure-lowering effects of azilsartan were noninferior to those of candesartan, and the urinary albumin-to-Cr ratio was not different between the 2 groups. Other results have varied depending on drug doses or the drugs which have been compared with azilsartan [23-25]. The present study demonstrated that azilsartan $(20 \mathrm{mg})$ significantly reduced the percent change in proteinuria as well as systolic blood pressure compared with candesar$\tan (8 \mathrm{mg})$. Proteinuria is an important biomarker of renal function, and a reduction in proteinuria during $A R B$ treatment is associated with reno-protective effects in hypertensive patients with CKD [5]. Our results suggest that azilsartan may be useful in the treatment of CKD patients with proteinuria.

In the present study, the differences in the percent changes in the UPCR between the azilsartan and candesartan groups were $34.6 \%$ at $1 \mathrm{EP}$ and $19.7 \%$ at $2 \mathrm{EP}$, respectively. Azilsartan reduced proteinuria compared with candesartan during the course of the study. We demonstrated that the significant reduction in proteinuria induced by azilsartan was associated with reduced blood pressure. The antiproteinuric effect may be associated with both the antihypertensive and azilsartan-mediated direct effects on the kidney. Azilsartan has an original component, a 5-oxo-1,2,4 oxadiazole in a tetrazole ring, and this structure has been reported to induce strong inverse agonism in and bind tightly to angiotensin II type 1 receptors compared with other ARBs [10, 20]. In vitro, the inhibitory effects of azilsartan mediated through binding to angiotensin II and angiotensin II type 1 receptors were stronger than those of other ARBs [10]. This strong binding of azilsartan to angiotensin II type 1 receptors is thought to be associated with long and strong antihypertensive effects in a clinical setting. ARBs demonstrate reno-protective effects, and these effects are partially mediated by direct effects on the kidney which are 
independent of antihypertensive effects [16]. Takami et al. [21] demonstrated that the changes in urinary angiotensinogen, which is a biomarker of intrarenal RAS activation [26], were associated with the changes in the urinary albumin-to-Cr ratio; however, they were not associated with the changes in blood pressure. In a study in Zucker diabetic fatty rats, azilsartan decreased proteinuria compared with candesartan, although these drugs did not affect blood pressure [27]. We demonstrated that azilsartan decreased proteinuria and blood pressure significantly compared with candesartan, and our results are consistent with those of previous studies. These effects might be associated with the strong inhibitory effect to angiotensin II type 1 receptors by azilsartan compared to the other ARBs. However, further studies are needed to clarify direct effects in the kidney produced by strong RAS inhibition of azilsartan.

Azilsartan $(20 \mathrm{mg})$ significantly reduced blood pressure compared with candesartan in the current study. This result is consistent with that of previous studies of azilsartan and azilsartan medoxomil, a prodrug of azilsartan, which showed that the blood pressure-reducing effects of azilsartan and azilsartan medoxomil might be even stronger than those of other ARBs [20-22, 28-34]. In the current study, the differences in systolic blood pressure changes produced by azilsartan and candesartan were 5.2 and $3.6 \mathrm{~mm} \mathrm{Hg}$ at $1 \mathrm{EP}$ and $2 \mathrm{EP}$, respectively. These differences were small, but important. A $10 \mathrm{~mm} \mathrm{Hg}$ reduction in systolic blood pressure led to a $13 \%$ reduction in all-cause mortality, in a meta-analysis [35]. Even a $2 \mathrm{~mm} \mathrm{Hg}$ reduction in systolic blood pressure was associated with a $4 \%$ lower risk of coronary death and a $6 \%$ lower risk of stroke death [36]. The association between a reduction in blood pressure and proteinuria varied because of differences in baseline blood pressure levels in previous studies $[4,16,37-42]$. In studies in which the average baseline blood pressure was not in the hypertensive range and an RAS inhibitor was used, a $1 \mathrm{~mm} \mathrm{Hg}$ reduction in mean blood pressure was associated with a $4.9-18.2 \%$ reduction in proteinuria [37-42]. In the current study, a $1 \mathrm{~mm} \mathrm{Hg}$ increase in mean blood pressure was associated with an $8.2 \%$ increase in proteinuria in the candesartan group, and this result was consistent with previous studies. These results indicated that a small change in blood pressure had a major impact on a change in proteinuria in patients within a hypertensive blood pressure range. Furthermore, the significant lower blood pressure in the azilsartan group compared to the candesartan group observed at 1EP is also important in the present study. The stabilization times of systolic blood pres-

Antiproteinuric Effect of Azilsartan in CKD sure produced by azilsartan and candesartan were shown to be 7.1 and 11.0 days, respectively [43]. It was demonstrated in a clinical study that the prompt achievement of target blood pressure is important for the prevention of cardiovascular events [44]. In the present study, azilsartan lowered blood pressure significantly and rapidly. These results might provide meaningful clinical benefits for patients.

Azilsartan did not produce increased adverse effects compared with candesartan. Laboratory findings did not suggest any clinically severe changes in renal function and potassium status. During the crossover period, 1 patient was hospitalized because of a bone fracture during candesartan treatment, and 1 patient was hospitalized because of an abdominal aortic aneurysm during azilsartan treatment. However, these events are not associated with the study drugs.

The current study had some limitations. First, it was designed to evaluate the short-term effect of azilsartan and candesartan and did not include hard endpoints. Second, we selected a crossover design, which is consistent with previous studies using ARBs [19, 45, 46]. This was mainly because of the sample size. We did not detect a significant carryover and period effect, except for a period effect of the eGFR at 2EP, and we attribute this to the natural history of CKD. Third, the sample size was smaller than we had previously calculated. We had assumed a $15 \%$ reduction in proteinuria, but the difference was larger in the study. Fourth, antihypertensive and diuretic drugs were changed in some patients as previously permitted, and significant differences in diastolic blood pressure, the percent change in diastolic blood pressure, and urinary protein excretion at $1 \mathrm{EP}$ had disappeared at $2 \mathrm{EP}$. This means that azilsartan rapidly decreased blood pressure and proteinuria, and the primary physician changed antihypertensive and diuretic drugs to achieve target blood pressure. The rapid decrease in blood pressure by azilsartan and dose titration of the other ARBs was also observed in a clinical trial comparing azilsartan medoxomil and other ARBs [23]. Fifth, during the run-in period, we administered azilsartan, and we excluded patients who were intolerant of azilsartan to avoid misleading results. Sixth, the dose of azilsartan and candesartan used in the current study was lower than the dose used in previous studies $[47,48]$ and Western countries. In Japan, the maximum dose of candesartan permitted for hypertensive patients with renal injury is $8 \mathrm{mg}$ and the maximum dose of azilsartan permitted is $40 \mathrm{mg}$. In the context of Japan, we chose $20 \mathrm{mg}$ of azilsartan and $8 \mathrm{mg}$ of candesartan in the current study. 


\section{Conclusion}

The current study demonstrated that azilsartan decreased proteinuria and blood pressure significantly compared with candesartan without severe adverse events. Azilsartan may be superior to candesartan in terms of reno-protective and antihypertensive effects in patients with CKD.

\section{Acknowledgements}

We thank the study investigators: Dr. Takashi Deguchi, Dr. Shoko Hasegawa, Dr. Fumitada Hattori, Dr. Harumichi Higashi, Dr. Hideki Hirakata, Dr. Makoto Hirakawa, Dr. Tadashi Hirano, Dr. Kei Hori, Dr. Itsuko Ishida, Dr. Ritsuko Katafuchi, Dr. Hiroshi Kimura, Dr. Koji Mitsuiki, Dr. Tohru Mizumasa, Dr. Hitoshi Nagara, Dr. Kaneyasu Nakagawa, Dr. Masaru Nakayama, Dr. Aya Shima, Dr. Koji Sugawara, Dr. Masatomo Taniguchi, Dr. Masanori Tokumoto, and Dr. Tetsuhiko Yoshida. We thank Dr. Toshiharu Ninomiya (professor of the Department of Epidemiology and Public Health, Graduate School of Medical Sciences, Kyushu University) for his valuable advice in study design. We also thank Ms. Kuniko Watanabe and Ms. Noriko Noda for their helpful secretarial assistance. We express our deep gratitude for the support of all the physicians who kindly participated in this study. We thank Conn Hastings, PhD, from Edanz Group (https://en-author-services.edanzgroup.com/ac) for editing a draft of the manuscript.

\section{Statement of Ethics}

This study was performed in accordance with the Declaration of Helsinki, approved by the Independent Review Board of Kyusyu University Hospital (Approval number 24-023), and registered at the University Hospital Medical Information Network Clinical Trials Registry (UMIN-CTR; trial identification number: UMIN000008597) in Japan. This study was also approved by an Ethics Committee in each study center. Patients were required to provide written informed consent.

\section{Conflict of Interest Statement}

Ka.T. and T.K. have received honoraria and grants from Takeda Pharmaceutical Co., Ltd. The other authors declare no conflict of interest.

\section{Funding Sources}

This study was funded by a grant from Takeda Pharmaceutical Co., Ltd.

\section{Author Contributions}

Research idea and study design: T.S. and Ka.T.; data acquisition: T.S., Ka.T., H.Y., H.T., S.Y., S.T., A.T., M.E., K.F., Ku.T., and T.N.; data analysis/interpretation: T.S., Ka.T., and H.Y.; statistical analysis: T.S., Ka.T., and H.Y.; supervision or mentorship: T.K. Each author contributed important intellectual content during manuscript drafting or revision and accepts accountability for the overall work by ensuring that questions pertaining to the accuracy or integrity of any portion of the work are appropriately investigated and resolved. All authors reviewed the manuscript and approved the final version for publication. Ka.T. takes responsibility that this study has been reported honestly, accurately, and transparently; that no important aspects of the study have been omitted; and that any discrepancies from the study as planned (and, if relevant, registered) have been explained.

\section{References}

1 Nishiyama A, Seth DM, Navar LG. Angiotensin II type 1 receptor-mediated augmentation of renal interstitial fluid angiotensin II in angiotensin II-induced hypertension. J Hypertens. 2003 Oct;21(10):1897-903.

2 Nishiyama A, Yoshizumi M, Rahman M, Kobori H, Seth DM, Miyatake A, et al. Effects of AT1 receptor blockade on renal injury and mitogen-activated protein activity in Dahl salt-sensitive rats. Kidney Int. 2004 Mar; 65(3):972-81.

3 Kobori H, Nangaku M, Navar LG, Nishiyama A. The intrarenal renin-angiotensin system: from physiology to the pathobiology of hypertension and kidney disease. Pharmacol Rev. 2007 Sep;59(3):251-87.
4 Brenner BM, Cooper ME, de Zeeuw D, Keane WF, Mitch WE, Parving HH, et al. Effects of losartan on renal and cardiovascular outcomes in patients with type 2 diabetes and nephropathy. N Engl J Med. 2001 Sep 20; 345(12):861-9.

5 de Zeeuw D, Remuzzi G, Parving HH, Keane WF, Zhang Z, Shahinfar S, et al. Proteinuria, a target for renoprotection in patients with type 2 diabetic nephropathy: lessons from RENAAL. Kidney Int. 2004 Jun;65(6):2309-20.

6 Weinberg MS, Weinberg AJ, Cord R, Zappe $\mathrm{DH}$. The effect of high-dose angiotensin II receptor blockade beyond maximal recommended doses in reducing urinary protein excretion. J Renin Angiotensin Aldosterone Syst. 2001 Mar;2(1_suppl):S196-8.
7 Burgess E, Muirhead N, Rene de Cotret P, Chiu A, Pichette V, Tobe S. Supramaximal dose of candesartan in proteinuric renal disease. J Am Soc Nephrol. 2009 Apr;20(4):893900.

8 Parving HH, Brenner BM, McMurray JJ, de Zeeuw D, Haffner SM, Solomon SD, et al. Cardiorenal end points in a trial of aliskiren for type 2 diabetes. N Engl J Med. 2012 Dec 6; 367(23):2204-13.

9 Makani H, Bangalore S, Desouza KA, Shah A, Messerli FH. Efficacy and safety of dual blockade of the renin-angiotensin system: metaanalysis of randomised trials. BMJ. 2013 Jan 28;346:f360. 
10 Ojima M, Igata H, Tanaka M, Sakamoto H, Kuroita T, Kohara Y, et al. In vitro antagonistic properties of a new angiotensin type 1 receptor blocker, azilsartan, in receptor binding and function studies. J Pharmacol Exp Ther. 2011 Mar;336(3):801-8.

11 Committee of revision of clinical practice guidebook 2012 for diagnosis and treatment of CKD. Clinical practice guidebook for diagnosis and treatment of chronic kidney disease 2012. Tokyo: Tokyo Igakusha; 2012.

12 Matsuo S, Imai E, Horio M, Yasuda Y, Tomita K, Nitta K, et al. Revised equations for estimated GFR from serum creatinine in Japan. Am J Kidney Dis. 2009 Jun;53(6):98292.

13 Fujisaki K, Tsuruya K, Nakano T, Taniguchi M, Higashi H, Katafuchi R, et al. Impact of combined losartan/hydrochlorothiazide on proteinuria in patients with chronic kidney disease and hypertension. Hypertens Res. 2014 Nov;37(11):993-8.

14 Rossing K, Christensen PK, Jensen BR, Parving HH. Dual blockade of the renin-angiotensin system in diabetic nephropathy: a randomized double-blind crossover study. Diabetes Care. 2002 Jan;25(1):95-100.

15 Ogawa S, Takeuchi K, Mori T, Nako K, Tsubono Y, Ito S. Effects of monotherapy of temocapril or candesartan with dose increments or combination therapy with both drugs on the suppression of diabetic nephropathy. Hypertens Res. 2007 Apr;30(4):325-34.

16 Parving HH, Lehnert $\mathrm{H}$, Bröchner-Mortensen J, Gomis R, Andersen S, Arner P, et al. The effect of irbesartan on the development of diabetic nephropathy in patients with type 2 diabetes. N Engl J Med. 2001 Sep 20;345(12): 870-8.

17 Ohishi M, Takagi T, Ito N, Tatara Y, Hayashi $\mathrm{N}$, Shiota A, et al. Renal protective effect in hypertensive patients: the high doses of angiotensin II receptor blocker (HARB) study. Hypertens Res. 2007 Sep;30(12):1187-92.

18 Takahara M, Shiraiwa T, Shindo M, Arai A, Kusuda Y, Katakami N, et al. Efficacy and safety of 10-mg azilsartan compared with 8-mg candesartan cilexetil in Japanese patients with hypertension: a randomized crossover non-inferiority trial. Hypertens Res. 2014 Sep;37(9):852-7.

19 Nakayama S, Watada H, Mita T, Ikeda F, Shimizu T, Uchino $\mathrm{H}$, et al. Comparison of effects of olmesartan and telmisartan on blood pressure and metabolic parameters in Japanese early-stage type- 2 diabetics with hypertension. Hypertens Res. 2008 Jan;31(1):7-13.

20 Shiga Y, Miura SI, Motozato K, Norimatsu K, Yano M, Hitaka Y, et al. Comparison of efficacy and safety of azilsartan and olmesartan in patients with essential hypertension. Int Heart J. 2017 May 31;58(3):416-21.

21 Takami T, Okada S, Saito Y, Nishijima Y, Kobori $\mathrm{H}$, Nishiyama A. Effects of olmesartan and azilsartan on albuminuria and the intrarenal renin-angiotensin system. World J Res Rev. 2018 Jan;6(1):7-10.
22 Kakio Y, Uchida HA, Umebayashi R, Takeuchi H, Okuyama Y, Hanayama Y, et al. Practical efficacy of olmesartan versus azilsartan in patients with hypertension: a multicenter randomized-controlled trial (MUSCAT-4 study). Blood Press Monit. 2017 Apr;22(2): 59-67.

23 Bakris GL, Zhao L, Kupfer S, Juhasz A, Hisada $\mathrm{M}$, Lloyd E, et al. Long-term efficacy and tolerability of azilsartan medoxomil/chlorthalidone vs. olmesartan medoxomil/hydrochlorothiazide in chronic kidney disease. J Clin Hypertens. 2018 Apr;20(4):694-702.

24 Ishii T, Yasuda M, Saito Y, Mori Y, Hayashi $\mathrm{T}$, Uemura H, et al. Examination of the effect of changing to azilsartan from candesartan in renal transplant patients. Transplant Proc. 2014;46(2):492-5.

25 Sezai A, Osaka S, Yaoita H, Arimoto M, Hata $\mathrm{H}$, Shiono $\mathrm{M}$, et al. Changeover trial of azilsartan and olmesartan comparing effects on the renin-angiotensin-aldosterone system in patients with essential hypertension after cardiac surgery (CHAOS Study). Ann Thorac Cardiovasc Surg. 2016 Jun 20;22(3):161-7.

26 Kobori H, Alper AB Jr, Shenava R, Katsurada A, Saito T, Ohashi N, et al. Urinary angiotensinogen as a novel biomarker of the intrarenal renin-angiotensin system status in hypertensive patients. Hypertension. 2009 Feb;53(2): 344-50.

27 Kusumoto K. [In vitro and in vivo pharmacological profiles of a novel angiotensin type 1-receptor blocker, azilsartan]. Nippon Yakurigaku Zasshi. 2012 Jun;139(6):236-40.

28 Rakugi H, Enya K, Sugiura K, Ikeda Y. Comparison of the efficacy and safety of azilsartan with that of candesartan cilexetil in Japanese patients with grade I-II essential hypertension: a randomized, double-blind clinical study. Hypertens Res. 2012 May;35(5):552-8.

29 Rakugi H, Kario K, Enya K, Igeta M, Ikeda Y. Effect of azilsartan versus candesartan on nocturnal blood pressure variation in Japanese patients with essential hypertension. Blood Press. 2013 Sep;22(Suppl 1):22-8.

30 Rakugi H, Kario K, Enya K, Sugiura K, Ikeda Y. Effect of azilsartan versus candesartan on morning blood pressure surges in Japanese patients with essential hypertension. Blood Press Monit. 2014 Jun;19(3):164-9.

31 Bakris GL, Sica D, Weber M, White WB, Roberts A, Perez A, et al. The comparative effects of azilsartan medoxomil and olmesartan on ambulatory and clinic blood pressure. J Clin Hypertens. 2011 Feb;13(2):81-8.

32 Sica D, White WB, Weber MA, Bakris GL, Perez A, Cao C, et al. Comparison of the novel angiotensin II receptor blocker azilsartan medoxomil vs. valsartan by ambulatory blood pressure monitoring. J Clin Hypertens. 2011 Jul;13(7):467-72.
33 White WB, Weber MA, Sica D, Bakris GL, Perez A, Cao C, et al. Effects of the angiotensin receptor blocker azilsartan medoxomil versus olmesartan and valsartan on ambulatory and clinic blood pressure in patients with stages 1 and 2 hypertension. Hypertension. 2011 Mar;57(3):413-20.

34 White WB, Cuadra RH, Lloyd E, Bakris GL, Kupfer S. Effects of azilsartan medoxomil compared with olmesartan and valsartan on ambulatory and clinic blood pressure in patients with type 2 diabetes and prediabetes. J Hypertens. 2016 Apr;34(4):788-97.

35 Ettehad D, Emdin CA, Kiran A, Anderson SG, Callender T, Emberson J, et al. Blood pressure lowering for prevention of cardiovascular disease and death: a systematic review and metaanalysis. Lancet. 2016 Mar 5;387(10022):95767.

36 Stamler J, Rose G, Stamler R, Elliott P, Dyer A, Marmot M. INTERSALT study findings. Public health and medical care implications. Hypertension. 1989 Nov; 14(5):570-7.

37 Viberti G, Wheeldon NM; MicroAlbuminuria Reduction With VALsartan Study Investigators. Microalbuminuria reduction with valsartan in patients with type 2 diabetes mellitus: a blood pressure-independent effect. Circulation. 2002 Aug 6;106(6):672-8.

38 Zandbergen AA, Baggen MG, Lamberts SW, Bootsma AH, de Zeeuw D, Ouwendijk RJ. Effect of losartan on microalbuminuria in normotensive patients with type 2 diabetes mellitus. A randomized clinical trial. Ann Intern Med. 2003 Jul 15;139(2):90-6.

39 Maschio G, Cagnoli L, Claroni F, Fusaroli M, Rugiu C, Sanna G, et al. ACE inhibition reduces proteinuria in normotensive patients with IgA nephropathy: a multicentre, randomized, placebo-controlled study. Nephrol Dial Transplant. 1994;9(3):265-9.

40 Agha A, Amer W, Anwar E, Bashir K. Reduction of microalbuminuria by using losartan in normotensive patients with type 2 diabetes mellitus: a randomized controlled trial. Saudi J Kidney Dis Transpl. 2009 May;20(3):42935.

41 Ravid M, Savin H, Jutrin I, Bental T, Katz B, Lishner M. Long-term stabilizing effect of angiotensin-converting enzyme inhibition on plasma creatinine and on proteinuria in normotensive type II diabetic patients. Ann Intern Med. 1993 Apr 15;118(8):577-81.

42 Shen PC, He LQ, Yang XJ, Cao HX. Renal protection of losartan $50 \mathrm{mg}$ in normotensive Chinese patients with nondiabetic chronic kidney disease. J Investig Med. 2012 Oct; 60(7):1041-7.

43 Satoh M, Haga T, Hosaka M, Obara T, Metoki $\mathrm{H}$, Murakami T, et al. The velocity of antihypertensive effects of seven angiotensin II receptor blockers determined by home blood pressure measurements. J Hypertens. 2016 Jun;34(6):1218-23. 
44 Julius S, Kjeldsen SE, Weber M, Brunner HR, Ekman S, Hansson L, et al. Outcomes in hypertensive patients at high cardiovascular risk treated with regimens based on valsartan or amlodipine: the VALUE randomised trial. Lancet. 2004 Jun 19;363(9426):2022-31.

45 Masuda S, Tamura K, Wakui H, Kanaoka T, Ohsawa M, Maeda A, et al. Effects of angiotensin II type 1 receptor blocker on ambulatory blood pressure variability in hypertensive patients with overt diabetic nephropathy. Hypertens Res. 2009 Nov;32(11):950-5.
46 Slagman MC, Waanders F, Hemmelder MH, Woittiez AJ, Janssen WM, Lambers Heerspink HJ, et al. Moderate dietary sodium restriction added to angiotensin converting enzyme inhibition compared with dual blockade in lowering proteinuria and blood pressure: randomised controlled trial. BMJ. 2011 Jul 26;343:d4366.
47 Mogensen CE, Neldam S, Tikkanen I, Oren S, Viskoper R, Watts RW, et al. Randomised controlled trial of dual blockade of renin-angiotensin system in patients with hypertension, microalbuminuria, and non-insulin dependent diabetes: the candesartan and lisinopril microalbuminuria (CALM) study. BMJ. 2000 Dec 9;321(7274):1440-4.

48 Andersen NH, Poulsen PL, Knudsen ST, Poulsen SH, Eiskjaer H, Hansen KW, et al. Long-term dual blockade with candesartan and lisinopril in hypertensive patients with diabetes: the CALM II study. Diabetes Care. 2005 Feb;28(2):273-7. 